\title{
Prevalence of Different Bone Types on Implant Placement Site Using Cone-beam Computed Tomography Images
}

\author{
Amir Eskandarloo 1,* (D) , Karim Ghazikhanloo², Leyli Tapak ${ }^{\mathbf{3}}$, Hamed Sartipi ${ }^{4}$ \\ ${ }^{I}$ Associate Professor, Department of Oral and Maxillofacial Radiology, School of Dentistry, Hamadan University of Medical \\ Sciences, Hamadan, Iran \\ ${ }^{2}$ Assistant Professor, Department of Radiology, School of Paramedicine, Hamadan University of Medical Sciences, Hamadan, \\ Iran \\ 3 Assistant Professor, Department of Biostatistics, School of Public Health, Hamadan University of Medical Sciences, \\ Hamadan, Iran \\ ${ }^{4}$ Dentist, Hamadan University of Medical Sciences, Hamadan, Iran
}

* Corresponding Author: Amir Eskandarloo, Department of Oral and Maxillofacial Radiology, School of Dentistry, Hamadan University of Medical Sciences, Hamadan, Iran.Email: eskandarlo@ umsha.ac.ir

\begin{tabular}{|c|c|}
\hline & Abstract \\
\hline $\begin{array}{l}\text { Received: } 17.08 .2020 \\
\text { Accepted: } 09.11 .2020\end{array}$ & \multirow{3}{*}{$\begin{array}{l}\text { Background and Objective: Dental implants are a reliable tool for the } \\
\text { replacement of missing teeth, and the use of advanced imaging techniques } \\
\text { for the examination of the location of implants is on the rise these days. The } \\
\text { present study aimed to assess the frequency of different types of bone at the } \\
\text { implant site in different age groups in Cone Beam Computed Tomography } \\
\text { (CBCT) images. } \\
\text { Materials and Methods: A number of } 320 \text { CBCT images (ProMax (B)) } \\
\text { which were obtained for implant replacement were evaluated in this } \\
\text { descriptive study. Patients were assigned to } 10 \text { groups according to age (5- } \\
\text { year intervals) from } 20-70 \text { years old. The bone type was determined based } \\
\text { on Zarb and Lekholm classifications. In order to determine the bone type, } \\
\text { cross-sectional images with 1mm thickness were prepared in the most } \\
\text { suitable place for implant placement, and the resulting images were } \\
\text { evaluated by two observers. } \\
\text { Results: Out of } 1042 \text { implant sites, } 461581 \text { sites were in maxilla and } \\
\text { mandible, respectively. According to Kappa statistical analysis, there was a } \\
\text { significant inter-observers statistical correlation (82\%). the most commonly } \\
\text { observed bone types were D3, D2, D4, and D1, respectively. Bone type D3 } \\
\text { and D1 were the most and least prevalent types in men, whereas in women, } \\
\text { the most and least prevalent types were D3 and D1, respectively. The } \\
\text { prevalence of D3 and D4 bone type increases with age. Moreover, D1 and } \\
\text { D3 were the least and most prevalent bone types in younger ages, } \\
\text { respectively. } \\
\text { Conclusion: As evidenced by the obtained results, CBCT is a reliable tool } \\
\text { for identifying the type of bone in the implant placement area and } \\
\text { subsequently determining the prognosis of the treatment plan. } \\
\text { Keywords: Bone Type, Cone Beam Computed Tomography, Dental Implants }\end{array}$} \\
\hline $\begin{array}{l}\text { How to Cite this Article: } \\
\text { Eskandarloo A, Ghazikhanloo } \\
\text { K, Tapak L, Sartipi H. Preva- } \\
\text { lence of Different Bone Types } \\
\text { on Implant Placement Site Using } \\
\text { Cone-beam Computed Tomo- } \\
\text { graphy Images. Avicenna J Clin } \\
\text { Med. 2020; 27(3): 164-170. } \\
\text { DOI: } 10.29252 / \text { ajcm.27.3.164 }\end{array}$ & \\
\hline & \\
\hline
\end{tabular}




\title{
بررسى فراوانى انواع تيڤهاى استخوانى در محل جايكزينى ايميلنت در تصاوير توموكر افى كامييوترى با اشعه مخروطى
}

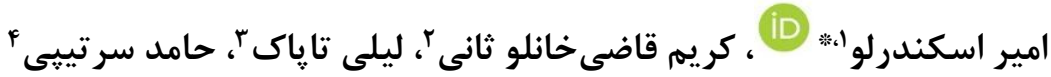 \\ ' دانشيار، كروه راديولوزى دهان و فك و صورت، دانشكده دندانيزشكى، دانشعاه علوم يزشكى همدان، همدان، ايران

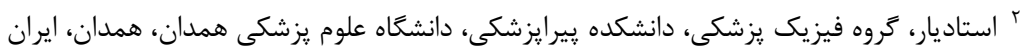

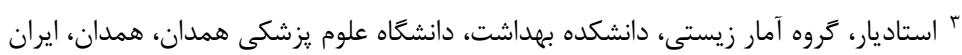

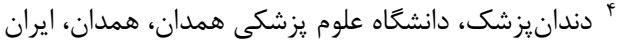

* نويسنده مسئول: امير اسكندرلو، تروه راديولوزى دهان و فك و صورت، دانشكده دندانيزشكى، دانشگاه علوم يزشكى همدان، همدان، ايران. ايميل:eskandarlo@umsha.ac.ir

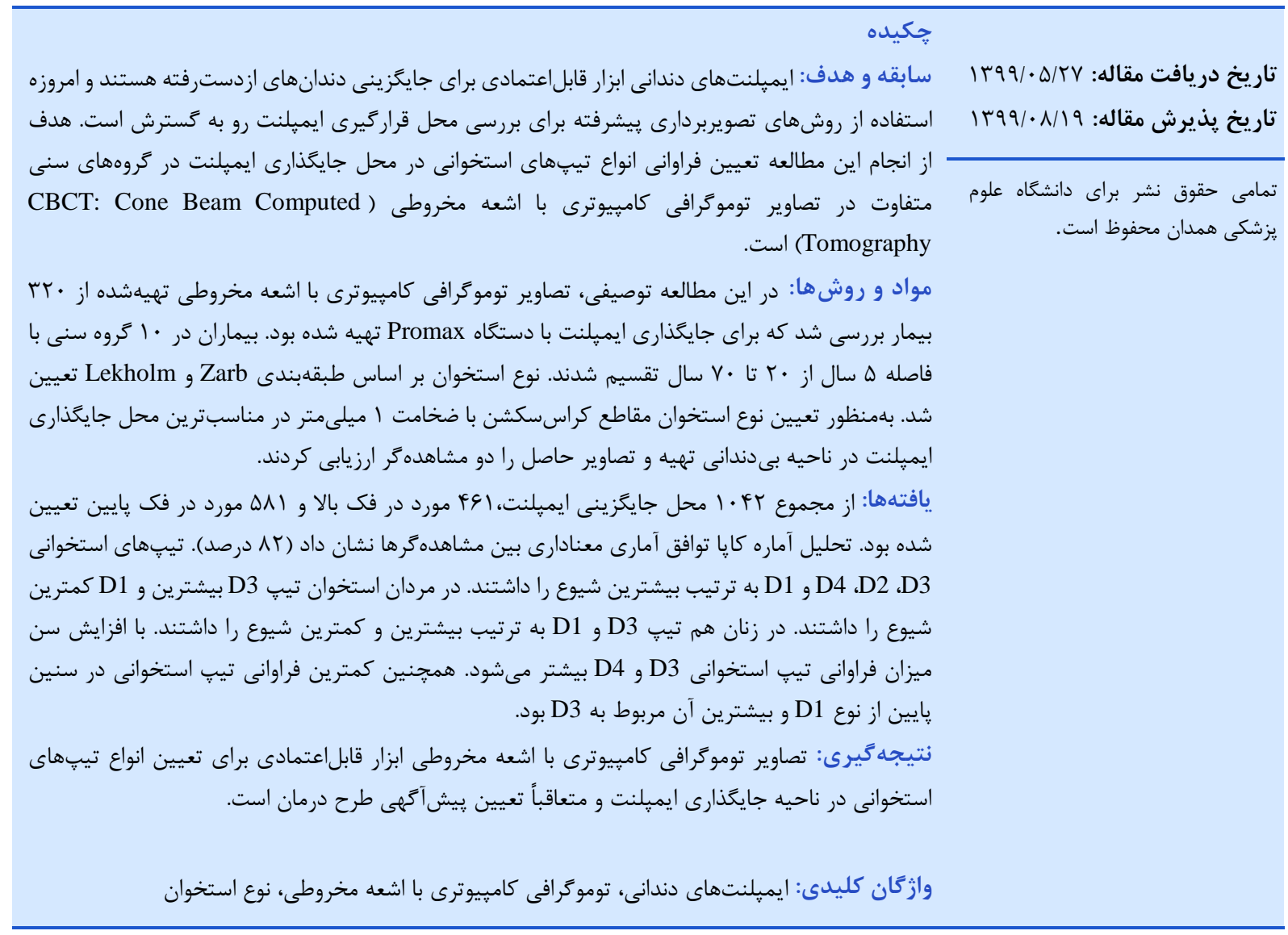

مقدمه

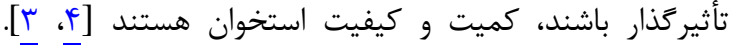
كيفيت استخوانى مناسب ييششرطى حياتى براى دستيابى به

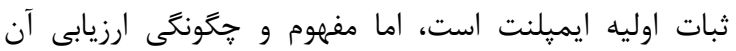
بهخوبى مشخص نشده است [ه]. تعريفهاى متفاوتى از كيفيت استخوان وجود دارد [ع]ـ، اما

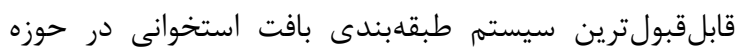

ايمبلنتهاى دندانى ابزار قابلاعتمادى براى جايكزينى إنى إنئ

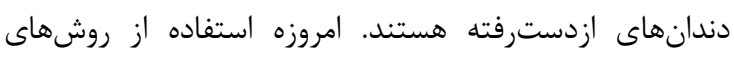

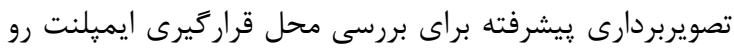

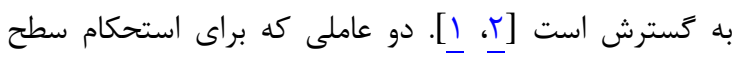

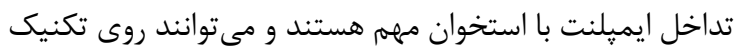

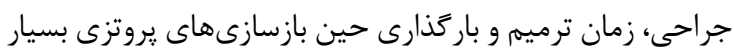


همدان صورت نكرفته است، اين مطالعه در نظر دارد فراوانى انواع تيڤهاى استخوانى را در محل جايگزينى ايميلنت در تصاوير

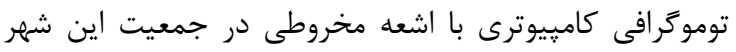
بررسى كند.

\section{مواد و روشها}

براى انجام اين يزوهش تصاوير توموگرافى كاميِيوترى با

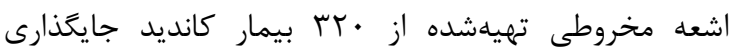

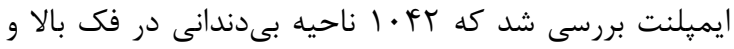

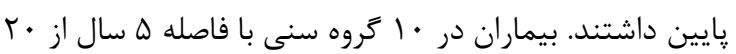

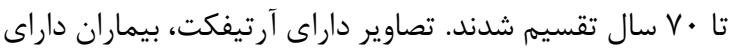
ضايعات استخوانى در ناحيه فك و صورت و افرادى كه اطلاعات

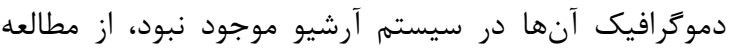

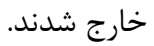

تصاوير توموكرافى كامييوترى با اشعه مخروطى بيماران با

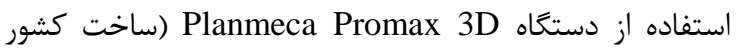

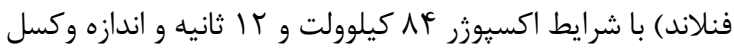

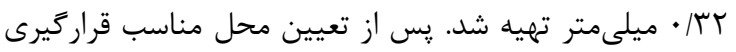

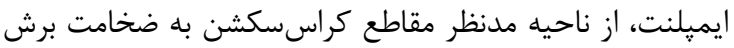

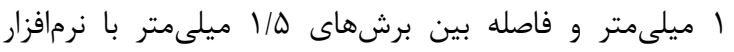
Romexis يك راديولوزيست فك و صورت و يك دستيار سال آخر رشته راديولوزى دهان، فك و صورت بهعنوان مشاهدهر انتخاب شدند.

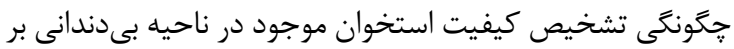

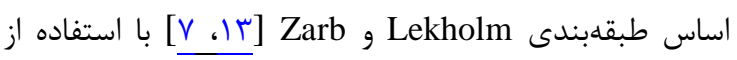
برشى كه براى هر ايميلنت انتخاب شده بود به مشاهدهَران

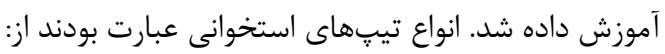

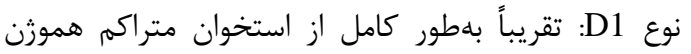
متشكل است.

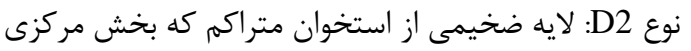

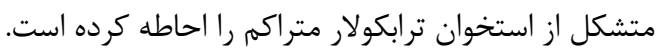

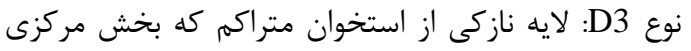
متشكل از استخوان ترابكولار متراكم را احاطه كرده است التان.

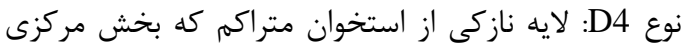

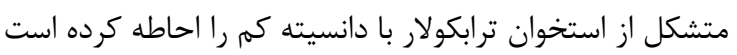

شرايط بررسى براى هر دو مشاهدهر يكسان بود. تصاوير

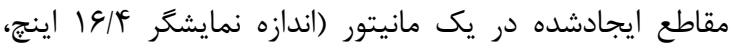

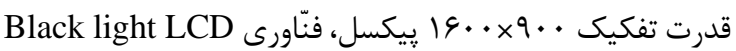

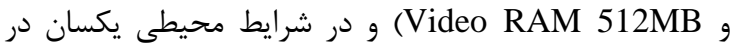

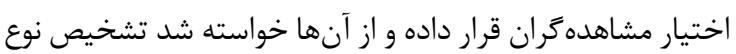
استخوان را بلصورت جشمى در جكليست مربوطه وارد كنند.

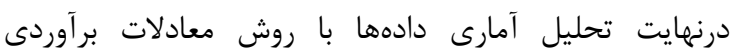

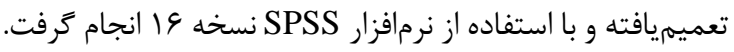

دندانيزشكى را Lekholm و Zarb معرفى كردند [V]. آنها دانسيته استخوان را بر اساس مشاهده ميزان استخوان كورتيكال در مقابل استخوان اسفنجى در ناحيه مشخصى از زائده به جهار

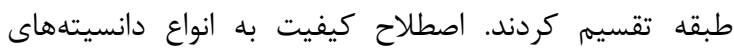

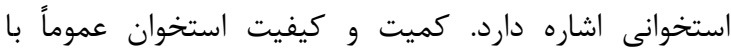

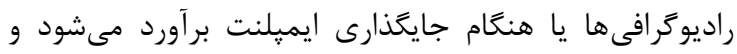
فرض بر اين است كه ايميلنتهايى كه در نواحى با كيفيت كم استخوان قرار مى گيرند، احتمال بيشترى براى شكست دائ دارند.

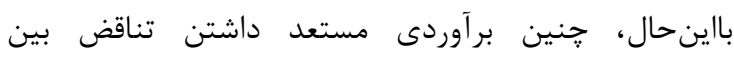

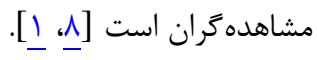

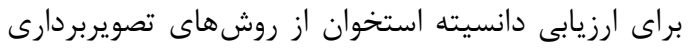

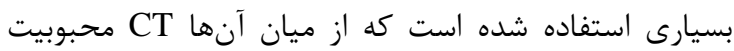

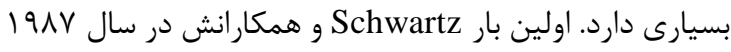

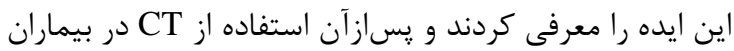

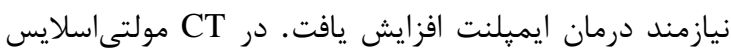

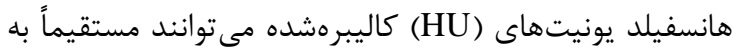

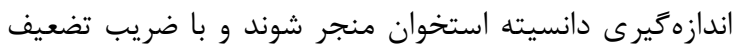

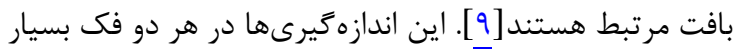

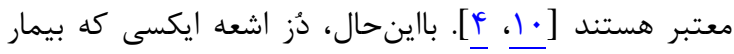
حين اسكن CT جذب مى كند، نسبت به ساير روشهاي

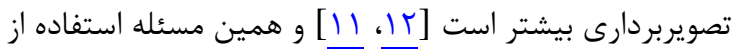

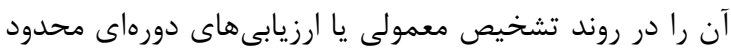

كرده است [بران]

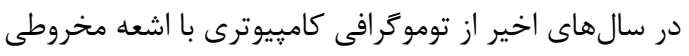
بهنوان (CBCT: Beam Computed Tomography Cone) ابزارى اختصاصى در تصويربردارى ناحيه سر و گردن استفاده

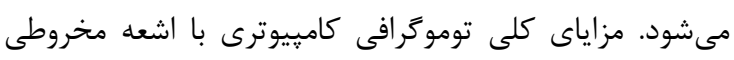

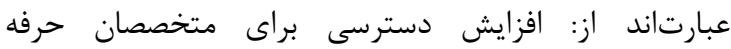

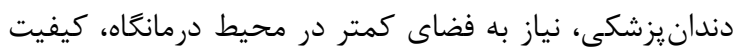

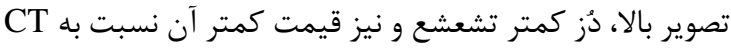

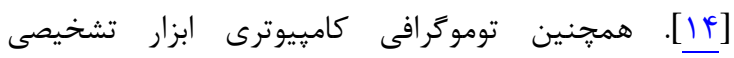

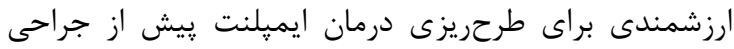

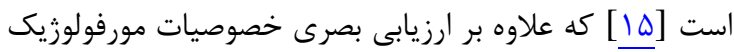

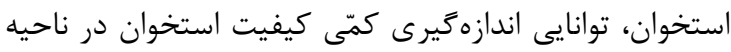

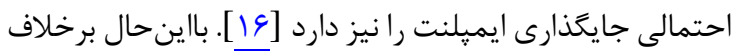
CT

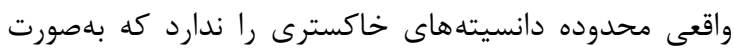

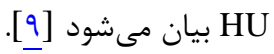

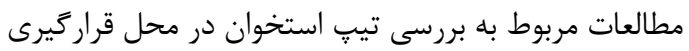
ايميلنت بسيار اندى هستند و مطالعه جامعى روى برى تصاوير

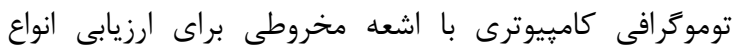

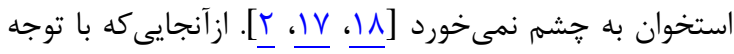
به منابع موجود تاكنون مطالعه جامعى درخصوص بردئ برسى انواع

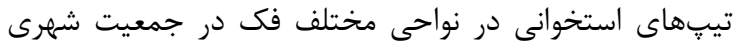




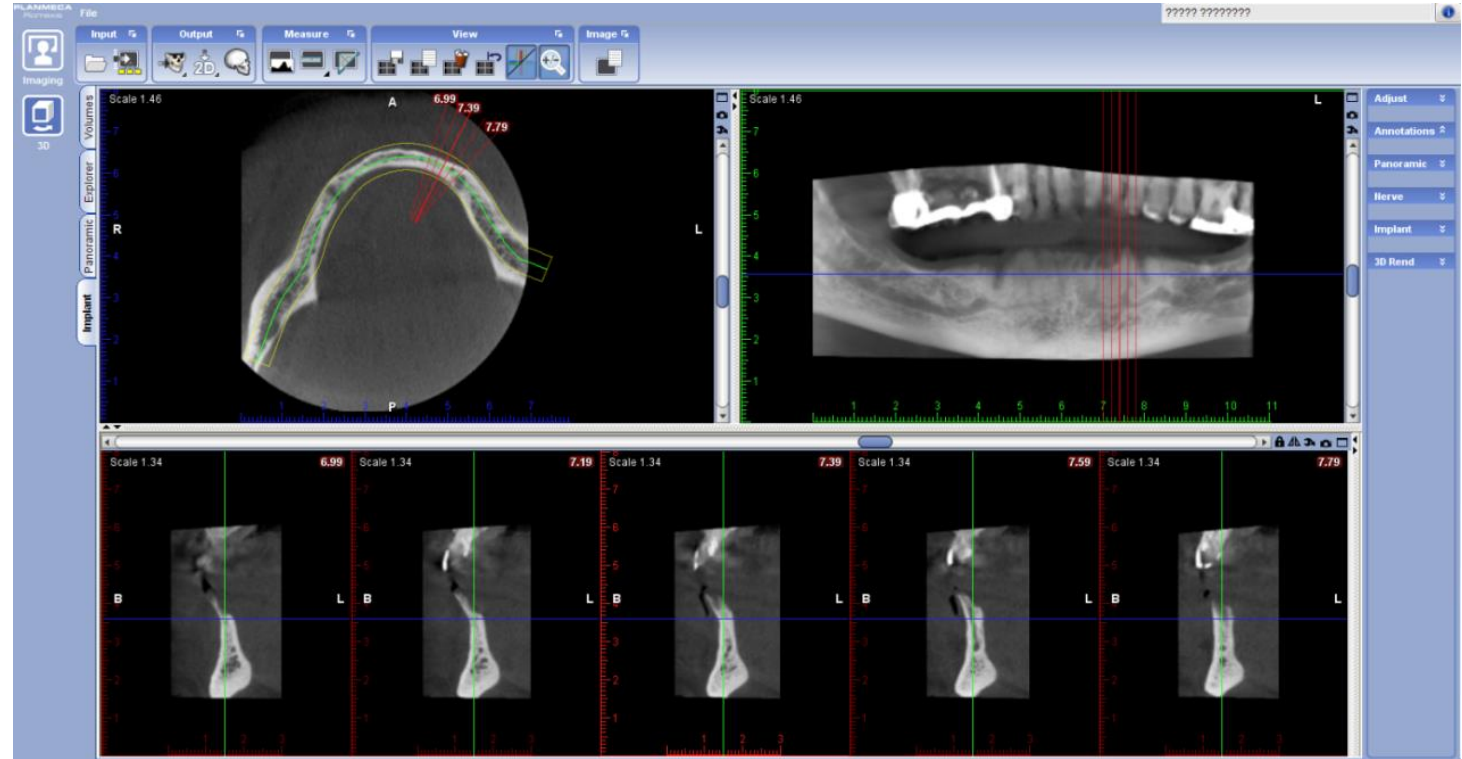

شكل ا: نماى كلى از تعيين مقاطع كراسسكن

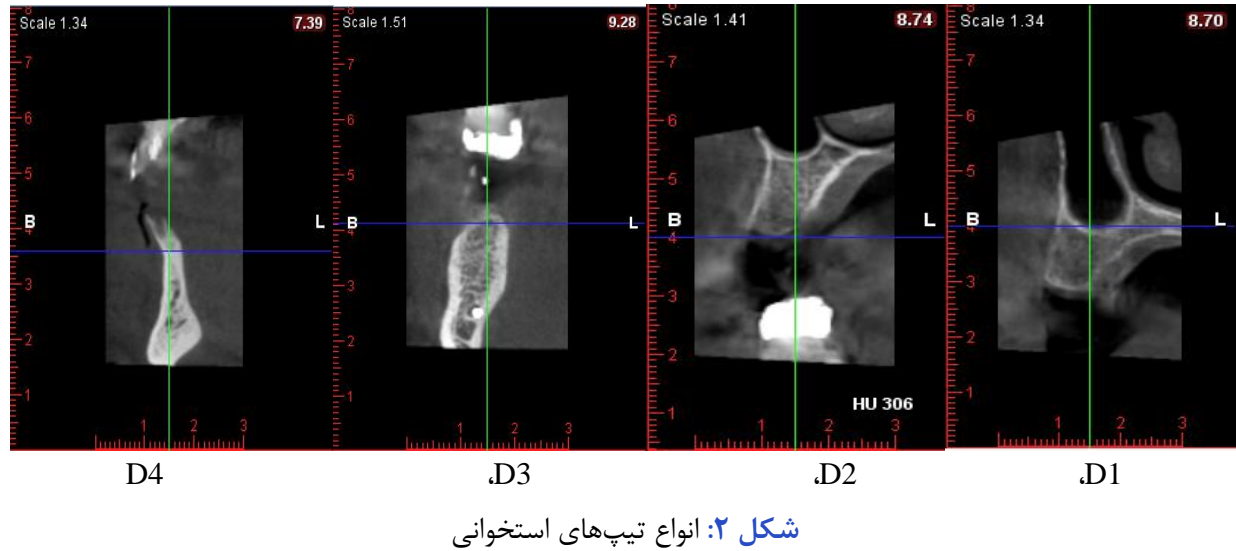

و هاه محل در زنان). ميزان شيوع انواع تيِهاى استخوانى در يافته ها

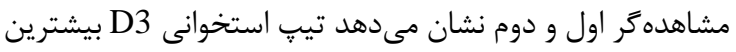

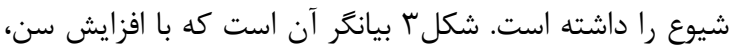

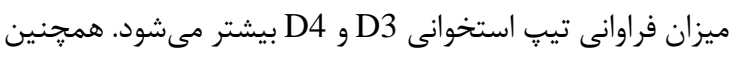
نمونههاى مطالعه شامل · ·r بيمار و تعداد محل جايكزينى

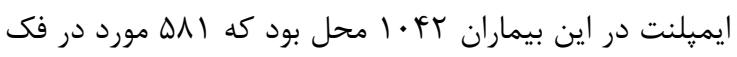

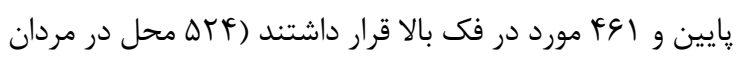

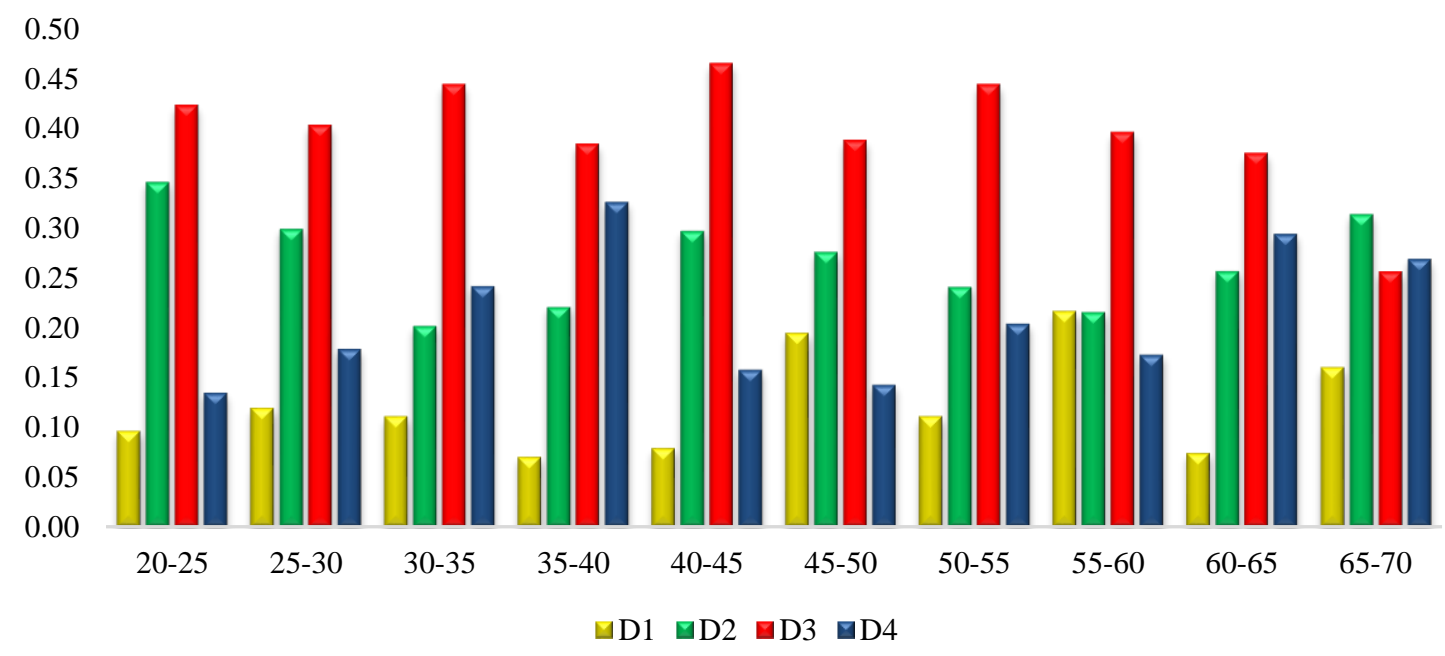

شكل "ז: ميزان شيوع تيبهاى استخوانى بر اساس كروههاى سنى 
جدول ا: ميزان شيوع انواع تيبهاى استخوانى بر اساس طبقهبندى Zarb و Lekholm در فى بالا و پايين

\begin{tabular}{|c|c|c|c|c|c|c|c|}
\hline \multirow[b]{2}{*}{ درصد } & \multicolumn{2}{|c|}{ ميانكين كل } & \multicolumn{2}{|c|}{ مشاهدهرَ دوم } & \multicolumn{2}{|c|}{ مشاهدهَر اول } & \multirow[b]{2}{*}{ تيب استخوانى } \\
\hline & فك بايين & فر بالا & فك يايين & فك بالا & فك يايين & فك بالا & \\
\hline$I T / T \Lambda$ & $|f / V|$ & $9 / \pi 1$ & $\Lambda \Delta$ & rV & 19 & iA & D1 \\
\hline$r V / I I$ & $r / / \Delta \Lambda$ & $f \cdot \mid \Lambda \Lambda$ & 119 & $1 \cdot r$ & IVA & 99 & D2 \\
\hline$r N / \cdot q$ & $r \Delta / \Lambda \Lambda$ & $k \cdot \mid \Lambda \Lambda$ & $r \cdot r$ & 114 & rIf & 191 & D3 \\
\hline$r T / Q$. & $|V| A \mid$ & $r N / F I$ & $1 \cdot r$ & (re & $1 \cdot r$ & Irs & D4 \\
\hline $1 \ldots$ & $1 \ldots$ & $1 \ldots$ & $\Delta \wedge 1$ & 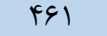 & $\Delta \wedge 1$ & $+\& 1$ & كل \\
\hline
\end{tabular}

جدول rا: ميزان شيوع انواع تيڤهاى استخوانى بر اساس طبقهبندى Zarb و Lekholm در مردان و زنان

\begin{tabular}{|c|c|c|c|c|c|c|c|}
\hline \multirow{3}{*}{ درصد } & \multicolumn{2}{|c|}{ ميانًَين كل } & \multicolumn{2}{|c|}{ مشاهدهرَ دوم } & \multicolumn{2}{|c|}{ مشاهدهَر اول } & \multirow{3}{*}{ تيب استخوانى } \\
\hline & زن & مرد & \multirow{2}{*}{ زن } & \multirow{2}{*}{ مرد - } & \multirow{2}{*}{ زن } & \multirow{2}{*}{ مرد } & \\
\hline & درصد & درصد & & & & & \\
\hline $\mid r / T \Lambda$ & $\Lambda / \cdot 1$ & $19 / 0$. & rq & ג & fr & 9 . & D1 \\
\hline$r V / I I$ & rm/le & $r \mid \cdot 1$ & $|r|$ & IV. & 119 & $10 \Delta$ & D2 \\
\hline rN/. 9 & $r \cdot / 1 \Delta$ & $r \& 1.9$ & $r \cdot q$ & 11. & $r \cdot V$ & 191 & D3 \\
\hline$r T / Q$. & TN/G9 & $|8 / 4|$ & 149 & 91 & $\mid F \wedge$ & 11 & D4 \\
\hline $1 \cdots$ & $1 \cdots$ & $1 \cdots$ & $\Delta 11$ & $\Delta Y F$ & $01 \Lambda$ & $\Delta Y F$ & كل \\
\hline
\end{tabular}

هنوز به فرايندى معمولى تبديل نشده است. دليل آن احتمالاً

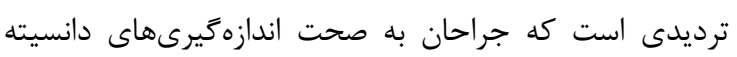

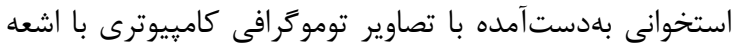

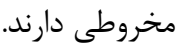
نتايج اين مطالعه بيانكر آن است كه با افزايش سن، ميزان

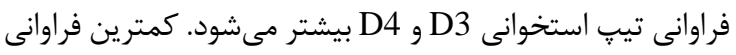

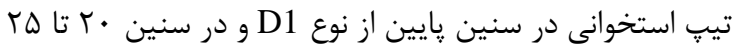

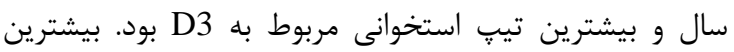

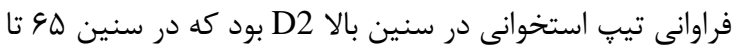

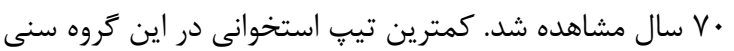

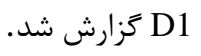

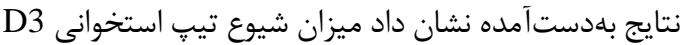

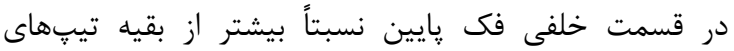

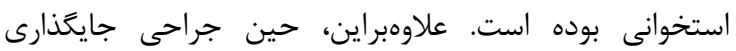

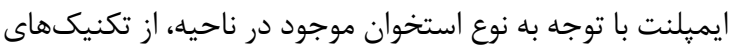

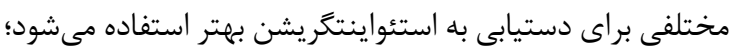

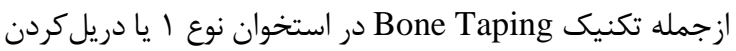

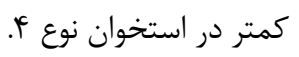

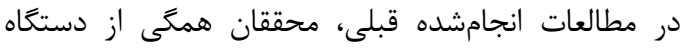

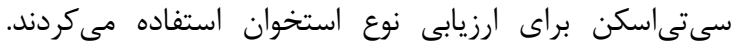

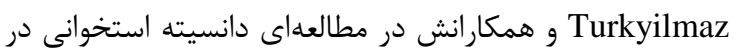
مناطق مختلف فك را بررسى كردند. نتايج آنان نشان داد داد بيشترين شيوع تيب استخوانى در نواحى قدامى و خلفى ماكزيلا

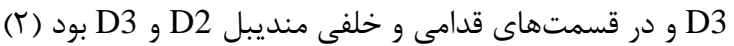
كه با نتايج بهدست آمده از مطالعه حاضر همسو است مندي
كمترين فراوانى تيڤ استخوانى در سنين پايين از نوع D1 و

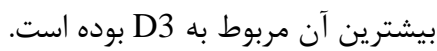

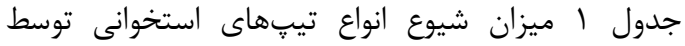

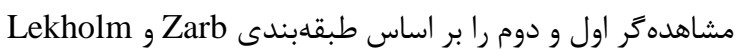
نشان مىدهد كه نتايج بيانكر اين است كه بيشترين تيب

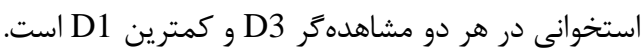

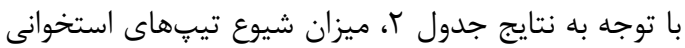
بهدستآمده توسط مشاهده دو جنس بيشترين شيوع و D1 كمترين شيوع را داشته است. ميزان توافق بين دو مشاهدهكر اول و دوم با استفاده از آماره كايا

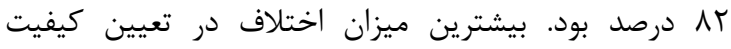

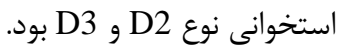

ارزيابى وضعيت استخوان بِيش از جراحى در طرحريزى إسى إنى

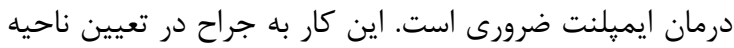

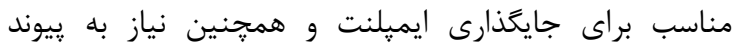

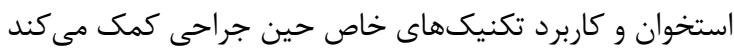

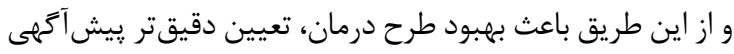

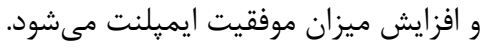

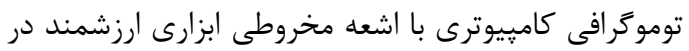

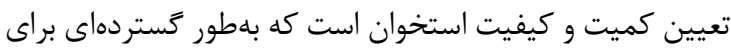

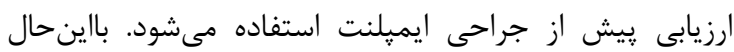

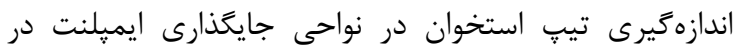

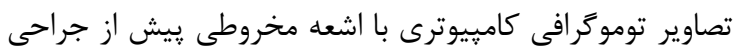


نتيجه تيرى

اين مطالعه تأكيد مىكند تصاوير توموكرافى كامييوترى با

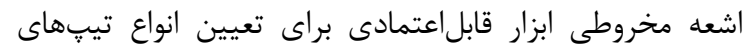

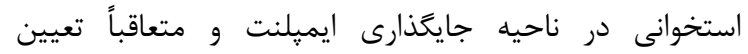

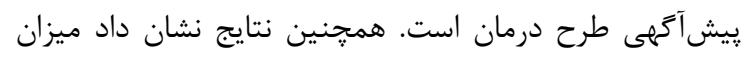

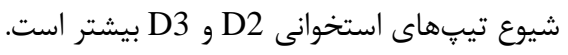

\section{تشكر و قلر دانى}

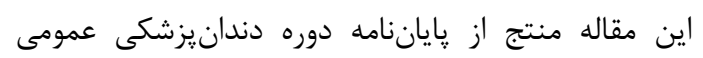

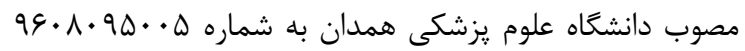

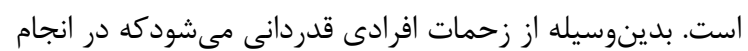
اين يروزه همكارى داشتند و از ما حمايت كردند.

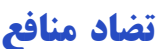
هيجَّونه تضاد منافعى گزارش نشده است.

ملاحظات اخلاقى اين طرح از كميته اخلاق دانشعاه علوم يزشكى همدان با كد

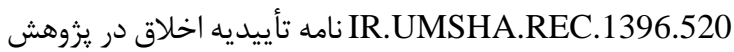

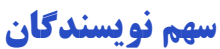

نويسنده اول (يزوهشكَر اصلى): مسئول مكاتبات، طراحى

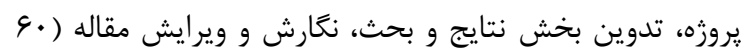

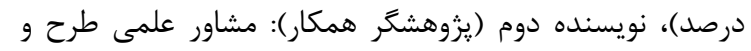

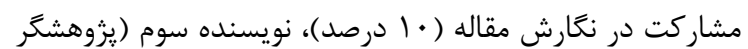

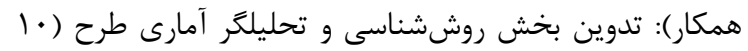

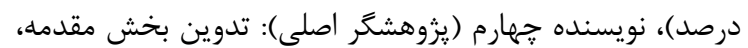
بازنخرى متون و جمعآورى نمونهها و دادهها ( · د درصد).

$$
\text { حمايت مالى } 1 \text { علوم يزشكى همدان انجام بايت مالى معاونت تحقيقات و فناورى دانشكاه }
$$

\section{REFERENCES}

1. Eskandarloo A, Abdinian M, Salemi F, Hashemzadeh Z, Safaei M. Effect of object location on the density measurement in cone-beam computed tomography versus multislice computed tomography. Dent Res J (Isfahan). 2012;9(Suppl 1):S81-7. PMID: 23814567

2. Turkyilmaz I, Tozum TF, Tumer C. Bone density assessments of oral implant sites using computerized tomography. J Oral Rehabil. 2007;34(4):267-72. PMID: 17371564 DOI: 10.1111/j.1365-2842.2006.01689.x

3. Jaffin RA, Berman CL. The excessive loss of Branemark fixtures in type IV bone: a 5-year analysis. J Periodontol. 1991;62(1):2-4. PMID: 2002427 DOI: 10.1902/jop.1991.62.1.2

4. Shahlaie M, Gantes B, Schulz E, Riggs M, Crigger M. Bone density assessments of dental implant sites: 1. Quantitative computed tomography. Int J Oral Maxillofac Implants.
و و همكارانش [19omolka

رسيدند كه قسمتهاى قدامى فك در مقايسه با قسمتهاى خلفى دانسيته استخوانى بيشترى دارند كه معمولاً اين نوع دانسيته بر اساس طبقهبندى Lekholm و Zarb تيي D1 وD2 را شامل مىشود. در مطالعه حاضر نيز همراستا با نتايج آنان قسمتهاى قدامى تيڤهاى استخوانى D1 و D2 فراوانى بيشترى داشتند. در مطالعه Truhlar و همكارانش [ •r] كه ״يراكندگى كيفيت استخوان را با كمك سيستم طبقهبندى Lekholm و Zarb بررسى كردند نيز نتايج بهدستآمده با مطالعه ما همسو بود؛ بدين معنى كه ميزان شيوع تيڤ استخوانى D1 و D4 مكرراً خيلى

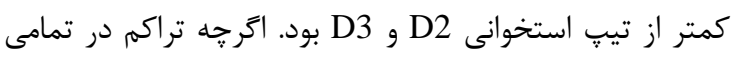
مناطق متفاوت بود، تيب استخوانى D1 و D2 در منديبل و D3

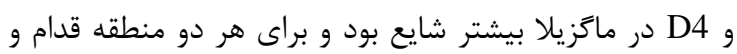

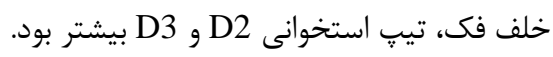

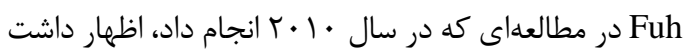

دانسيته استخوان ترابكولار عامل مهمى در دستيابى به نتايج مناسب است؛ زيرا استخوان ترابكولار مسئول پاسخ بيولوزيك و سايورت مكانيكى ايميلنت است. محدوده دانسيته استخوانى در D2 و D3 بسيار وسيع و بيشترين ميزان هميوشانى مقادير دانسيته نيز بين اين دو نوع استخوان بود [I/]. نتايج بهدستآمده در يزوهش حاضر با يافتههاى اين مطالعه همسو است. هر جند محققان از دستخاه سىتى اسكن براى مطالعات خود

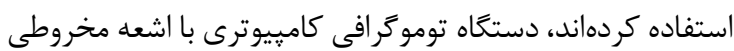
نيز مىتواند براى تعيين تييهاى استخوانى در محل جايخزينى ايميلنت كمك كننده باشد.

با وجود اينكه با افزايش سن، دانسيته استخوانى كاهش ييدا كرده است و به نظر مىرسد تيڤ استخوانى D3 و D4 بيشتر باشد، ولى در اين مطالعه در سنين بالا تيڤ استخوانى D1 و D2 شيوع بيشترى داشته است كه اين موضوع مىتواند به علت زيادتربودن بيمارانى باشد كه تمام دندانهاى خود را از دست داده بودند و براى اين بيماران معمولاً در نواحى قدامى ايميلنت

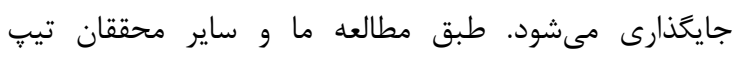
استخوانى D1 و D2 در نواحى قدامى شيوع بيشترى داشت.

2003;18(2):224-31. PMID: 12705300

5. Bergkvist G, Koh KJ, Sahlholm S, Klintstrom E, Lindh C. Bone density at implant sites and its relationship to assessment of bone quality and treatment outcome. Int J Oral Maxillofac Implants. 2010;25(2):321-8. PMID: 20369091

6. Eskandarloo A, Arabi R, Bidgoli M, Yousefi F, Poorolajal J. Association between marginal bone loss and bone quality at dental implant sites based on evidence from cone beam computed tomography and periapical radiographs. Contemp Clin Dent. 2019;10(1):36-41. PMID: 32015639 DOI: $10.4103 /$ ccd.ccd $185 \quad 18$

7. Lekholm U, Zarb G. Patient selection and preparation. In: Branemark PI, Zarb G, Alberktsson T, editors. Tissueintegrated prostheses:osseointegration in clinical dentistry. Chicago: Quintessence Pub Co; 1985. P. 199-209. 
8. White SC, Pharoah MJ. Oral radiology: principles and interpretation. $5^{\text {th }}$ ed. St. Louis: Mosby; 2019. P. 259.

9. Parsa A, Ibrahim N, Hassan B, Motroni A, van der Stelt P, Wismeijer D. Reliability of voxel gray values in cone beam computed tomography for preoperative implant planning assessment. Int J Oral Maxillofac Implants. 2012;27(6): 1438-42. PMID: 23189294

10. de Oliveira RC, Leles CR, Normanha LM, Lindh C, RibeiroRotta RF. Assessments of trabecular bone density at implant sites on CT images. Oral Surg Oral Med Oral Pathol Oral Radiol Endod. 2008;105(2):231-8. PMID: 18230392 DOI: 10.1016/j.tripleo.2007.08.007

11. Ekestubbe A, Thilander A, Grondahl K, Grondahl HG. Absorbed doses from computed tomography for dental implant surgery: comparison with conventional tomography. Dentomaxillofac Radiol. 1993;22(1):13-7. PMID: 8508935 DOI: $10.1259 / \mathrm{dmfr} .22 .1 .8508935$

12. Dula K, Mini R, van der Stelt PF, Lambrecht JT, Schneeberger P, Buser D. Hypothetical mortality risk associated with spiral computed tomography of the maxilla and mandible. Eur J Oral Sci. 1996;104(5-6):503-10. PMID: 9021317 DOI: 10.1111/j.1600-0722.1996.tb00133.x

13. Aranyarachkul P, Caruso J, Gantes B, Schulz E, Riggs M, Dus I, et al. Bone density assessments of dental implant sites: 2. Quantitative cone-beam computerized tomography. Int J Oral Maxillofac Implants. 2005;20(3):416-24. PMID: 15973953

14. Isoda K, Ayukawa Y, Tsukiyama Y, Sogo M, Matsushita Y, Koyano K. Relationship between the bone density estimated by cone-beam computed tomography and the primary stability of dental implants. Clin Oral Implants Res. 2012;23(7):832-6. PMID: 21545533 DOI: 10.1111/j.16000501.2011.02203.x
15. Angelopoulos $\mathrm{C}$, Aghaloo T. Imaging technology in implant diagnosis. Dent Clin North Am. 2011;55(1):141-58. PMID: 21094723 DOI: 10.1016/j.cden.2010.08.001

16. Valiyaparambil JV, Yamany I, Ortiz D, Shafer DM, Pendrys $\mathrm{D}$, Freilich M, et al. Bone quality evaluation: comparison of cone beam computed tomography and subjective surgical assessment. Int J Oral Maxillofac Implants. 2012;27(5): 1271-7. PMID: 23057044

17. Li FB, Yu LY, Cai YD, Xie C. Jaw bone density assessments of implant sites using spiral CT and Simplant software. Shanghai Kou Qiang Yi Хue. 2009;18(1):52-5. PMID: 19290428

18. Eskandarloo A, Saati S, Purabdolahi Ardakani M, Jamalpour M, Mezerji NM, Akheshteh V. Diagnostic accuracy of three cone beam computed tomography systems and periapical radiography for detection of fenestration around dental implants. Contemp Clin Dent. 2018;9(3):376-81. PMID: 30166830 DOI: $10.4103 /$ ccd.ccd_103_18

19. Homolka P, Beer A, Birkfellner W, Nowotny R, Gahleitner A, Tschabitscher M, et al. Bone mineral density measurement with dental quantitative $\mathrm{CT}$ prior to dental implant placement in cadaver mandibles: pilot study. Radiology. 2002;224(1): 247-52. PMID: 12091691 DOI: 10.1148/radiol.2241010948

20. Truhlar RS, Orenstein IH, Morris HF, Ochi S. Distribution of bone quality in patients receiving endosseous dental implants. J Oral Maxillofac Surg. 1997;55(12 Suppl 5):38-45. PMID: 9393425 DOI: 10.1016/s0278-2391(16)31196-X

21. Fuh LJ, Huang HL, Chen CS, Fu KL, Shen YW, Tu MG, et al. Variations in bone density at dental implant sites in different regions of the jawbone. J Oral Rehabil. 2010;37(5):346-51. PMID: 20113389 DOI: 10.1111/j.13652842.2010.02061.x 